Revista Eletrônica de Direito Processual - REDP.

Rio de Janeiro. Ano 15. Volume 22. Número 2. Maio a Agosto de 2021

Periódico Quadrimestral da Pós-Graduação Stricto Sensu em Direito Processual da UERJ

Patrono: José Carlos Barbosa Moreira (in mem.). ISSN 1982-7636. pp. 348-363

www.redp.uerj.br

\title{
O BEM-ESTAR COMO UM VALOR INTANGÍVEL DOS MÉTODOS DE RESOLUÇÃO DE CONFLITOS ${ }^{1}{ }^{2}$
}

\section{THE WELFARE AS AN INTANGIBLE VALUE OF THE CONFLICT RESOLUTION MECHANISMS}

Francisco Gorjón-Gómez Presidente da Associação Internacional de Métodos Alternativos de Resolução de Conflitos; Diretor do Doutorado em MASC da Universidade Autônoma de Nuevo León. Nuevo León, México. E-mail: fgorjon@hotmail.com

Karla Sáenz Doutora em Ciência Política pela Universidade Complutense de Madrid, Professora e Pesquisador da Universidade Autônoma de Nuevo León, México. Nível 1 do Sistema Nacional de Pesquisadores do Conselho Nacional de Ciência e Tecnologia do México. Nuevo León, México. E-mail: karla.saenzlp@uanl.edu.mx

RESUMO. O presente artigo trata dos valores intangíveis dos métodos de resolução de conflitos, visando desenvolver uma cultura de conciliação social.

PALAVRAS-CHAVE. bem-estar; valor intangível; métodos de resolução de conflitos

\footnotetext{
${ }^{1}$ Artigo recebido em 11/04/2021, sob dispensa de revisão.

${ }^{2}$ Artigo traduzido para o português pelos autores.
} 
Revista Eletrônica de Direito Processual - REDP.

Rio de Janeiro. Ano 15. Volume 22. Número 2. Maio a Agosto de 2021

Periódico Quadrimestral da Pós-Graduação Stricto Sensu em Direito Processual da UERJ

Patrono: José Carlos Barbosa Moreira (in mem.). ISSN 1982-7636. pp. 348-363

www.redp.uerj.br

ABSTRACT. This paper deals with the intangible values of conflict resolution mechanisms, aiming to develop a culture of social conciliation.

KEYWORDS. welfare; intangible value; conflict resolution mechanisms

\section{Introdução}

Os valores intangíveis da mediação e de outros MSCs são diversos, visando desenvolver uma cultura de conciliação social, traduzindo-se os benefícios dos MSCs para a sociedade em uma linguagem prática, em uma dúctil e eficiente a linguagem, para que a sociedade os compreenda, saiba que realmente terá benefícios e possa ser feliz.

A mediação é um caminho para o bem-estar e a felicidade, porque tem todos os elementos para poder determiná-la desta forma, bem como defini-la como política de bem-estar público, que influencia as nossas ações e a eventual solução de um conflito. Consequentemente, apresenta-se como um valor intangível substantivo para ganhar a vida bem, vivendo bem, alcançando uma qualidade de vida a partir da percepção de cada pessoa.

\section{1.- Valor de bem-estar}

Derivado dessas duas primeiras conjecturas básicas, é agora imperativo determinar qual é o valor que devemos dar ao bem-estar não como uma política, mas como um intangível, para saber seu lugar e seu significado no jogo da organização social, em o seu organograma, em correlação com a mediação, com a resolução de conflitos no seu processo de gestão e transformação, e na sua impressão nas ações de uma sociedade moderna, bem como a definição de que nela convergem outros valores, pela nossa experiência na promoção e divulgação dos MSCs.

Consideramos que o mais conveniente para saber o impacto que o bem-estar teria na sociedade, especialmente o bem-estar subjetivo percebido, seria o seu valor, o valor a que nos referiremos é o valor intangível, que é regido por um esquema positivo, o que é valioso para a percepção das pessoas, que podem ser assimilados como os benefícios que produz e que são 
Revista Eletrônica de Direito Processual - REDP.

Rio de Janeiro. Ano 15. Volume 22. Número 2. Maio a Agosto de 2021

Periódico Quadrimestral da Pós-Graduação Stricto Sensu em Direito Processual da UERJ

Patrono: José Carlos Barbosa Moreira (in mem.). ISSN 1982-7636. pp. 348-363

www.redp.uerj.br

recebidos diretamente por um usuário, um mediador, um conciliador, um árbitro ou aquele que conta com a ajuda de um negociador em qualquer transação comercial ou em conflito com o adversário, ou facilitador em processo de justiça restaurativa, enfim, pelo que ganhamos.

É preciso também definir em que cenário vamos nos colocar, em que ambiente e em que condições pretendemos fazê-lo. Sabemos de antemão que, como política pública, porém, aquela política pública que tem impacto, onde, para quem, em que sentido. Até agora apenas chamamos a atenção para a felicidade, para o livre arbítrio como os elementos determinantes de ambos, essenciais na gestão e transformação do conflito e no uso do MSC, mas em que estágio multidimensional nos situaremos historicamente e seu impacto sobre a organização social atual.

Um fenômeno que tem marcado a ação social nas últimas décadas, que bem pode ser a nossa razão de delimitação e a que nos referimos é a "violência estrutural", um fenômeno negativo que tem a ver com a nossa história, a nossa cultura, a nossa organização política e econômica, com os nossos costumes e como nos têm levado a aceitar coisas que repudiamos. Porém, por já fazer parte do cotidiano consentimos com eles e não só que, a eles submetemos à violência como fator determinante na nossa forma de nos organizarmos, que marca também o nosso grau de felicidade, antes infelicidade e falta de bem-estar.

É necessário, portanto, conhecer o seu contrapeso, quero dizer "paz estrutural", ela, como outras formas de paz, trabalha para aliviar, para reduzir o fenômeno da violência que tem caracterizado a sociedade nas últimas décadas e que apesar do esforço do Estado tem não conseguindo controlar, pelo contrário, tem vindo a aumentar.

Os elementos que compatibilizam a nossa proposta de paz estrutural, não só para gerar bem-estar, mas também para limitar e acabar com a violência, são a harmonia e a dignidade de que o ser humano necessita para viver em comunidade, pois requer o diálogo desde que partem da ideia do acordo, da liberdade e do livre arbítrio, bases inegáveis também do bem-estar, da felicidade e do MSC, emergindo deste discurso os agentes da paz, enquanto operadores da paz estrutural, a que nos referiremos mais tarde.

\section{2.- Justificativa para o valor dos intangíveis}


Revista Eletrônica de Direito Processual - REDP.

Rio de Janeiro. Ano 15. Volume 22. Número 2. Maio a Agosto de 2021

Periódico Quadrimestral da Pós-Graduação Stricto Sensu em Direito Processual da UERJ

Patrono: José Carlos Barbosa Moreira (in mem.). ISSN 1982-7636. pp. 348-363

www.redp.uerj.br

Definimos a necessidade e o ambiente de dar um valor e o tipo de valor ao bem-estar, isso é como um valor intangível do MSC, já existe um modelo para definir o que e como um fenômeno é um intangível, entendido como tudo podemos isolar e estudar cientificamente é um fenômeno.

Este modelo de avaliação já é conhecido pela comunidade científica $\mathrm{MSC}^{3}$ e tem sido utilizado na estratificação de várias investigações, porém, para merecê-lo, será tratado brevemente, visto que não é um obstáculo que você necessariamente o conheça, entendendo que a vocação deste trabalho é multidisciplinar e multidimensional, que é não dirigido apenas a advogados ou especialistas em MSC; dirige-se a todos os profissionais como futuros operadores e a toda a sociedade como futuros usuários, e é neste modelo que basearei minhas afirmações.

Um valor intangível é um método de avaliação que tem vários efeitos, incluindo dar significado e valor a uma ideia, a um sistema, a uma criação ou a um padrão ${ }^{4}$. Estes, por sua vez, convergem para que essa ideia possa ser aceita e operada sob certos cânones e integrada em um modelo de produção, seja industrial ou econômico, no nosso caso em um modelo social, que determina a ação das pessoas em comunidade. Este modelo surge da busca de fórmulas que nos permitem produzir estratégias para o uso dos MSC na solução de conflitos cotidianos, a partir da compreensão dos benefícios da gestão dos conflitos.

Tradicionalmente os MSC deram-se a conhecer por definição ou características próprias, vistas do ponto de vista jurídico, ao que limitava a sua esfera de influência, devido ao referido normativismo, foi então necessário criar um outro cenário, onde convergir a comunidade, ver e compreendê-los, era preciso traduzi-los, era preciso que falássemos a linguagem da sociedade, que esses benefícios se tornassem conceitos e esses conceitos reproduzissem um fenômeno que todos observaram e assimilaram.

Os conceitos subjacentes ao MSC são técnicos baseados na instrumentalização da negociação, mediação, conciliação, arbitragem, justiça restaurativa, já complexos pelo seu cunho normativo, porém, quando analisamos seus efeitos e o que eles produzem, percebemos

\footnotetext{
${ }^{3}$ Gorjón Gómez, F. J. (2017). Mediación, su valor intangible y efectos operativos. Una visión integradora de los Métodos Alternos de Solución de Conflictos. México: Tirant lo Blanch

${ }^{4}$ Álvarez Villanueva, C. (2012). Activos Intangibles: catalogación de metodos de valoración. Madrid: Fragua.
} 
Revista Eletrônica de Direito Processual - REDP.

Rio de Janeiro. Ano 15. Volume 22. Número 2. Maio a Agosto de 2021

Periódico Quadrimestral da Pós-Graduação Stricto Sensu em Direito Processual da UERJ

Patrono: José Carlos Barbosa Moreira (in mem.). ISSN 1982-7636. pp. 348-363

www.redp.uerj.br

sua ductilidade e como, em princípios tradicionalmente associados à sociedade, são fáceis de entender, Conseguimos reconciliá-los e fixá-los na mente das pessoas através do seu valor intangível, por exemplo o da felicidade, a felicidade é compreendida por todos, eles a conhecem, gostam ou não têm, mas todos sabem e compreendem, É a partir disso perspectiva de que se cria o modelo de Intangíveis do MSC, pois, partimos da ideia de todos os benefícios positivos que $\mathrm{o}$ acordo de mediação produz, já mostramos que o acordo produz perdão ${ }^{5}$, produz felicidade ${ }^{6}$.

Conceitos que se situam na genética social, conceitos que um velho ou uma criança compreendem, é então nesta lógica que pretendemos situar o bem-estar, com a vantagem de ser considerado sinónimo de felicidade e já definido como um intangível do MSC, agora nos resta determinar suas características distintivas, o bem-estar como modelo social que rege nossas vidas em comunidade.

Os valores intangíveis baseiam-se no capital intelectual das pessoas, dos criadores dessa ideia ou conceito, o que torna esse processo mais eficaz, são também características que os tornam diferentes dos outros, os tornam úteis, atrativos, mas principalmente valiosos ${ }^{7}$. Eles são uma fonte de benefícios, eles geram valor, e esse valor está baseado nas suas características distintivas, entenda isso os efeitos que eles produzem nas pessoas; delimitadas pela inovação que produzem, pelas práticas de gestão nelas impressas, pelos conflitos que resolve, pelo potencial positivo que conferem a uma empresa, uma instituição, uma pessoa no nosso caso uma sociedade, estes intangíveis carecem de substância física ${ }^{8}$, mas, sua imaterialidade permite que sejam identificáveis e controláveis de acordo com o ambiente onde são invocados ${ }^{9}$, como acontece nos MSCs.

Entendemos que não estamos nos referindo às suas características, são questões diferentes, pois enquanto os Intangíveis se concentram em suas considerações de valor distinto e seu efeito positivo. Por exemplo, simplicidade, seu valor é facilidade e com ela ocorre a implementação.

\footnotetext{
${ }^{5}$ Ramos Morales, M. L. (17 de Mayo de 2017). Tesis Doctoral. Los elementos del perdon en la mediación familiar. Monterrey, Nuevo León, México: UANL.

${ }^{6}$ Muñoz, R. (12 de novembro de 2019). Tesis Doctoral. La felicidad como valor intengible de la mediación. Monterrey, Nuevo León, México: UANL.

${ }^{7}$ Gorjón Gómez, F. J. (2017). Mediación, su valor intangible y efectos operativos. Una visión integradora de los Métodos Alternos de Solución de Conflictos. México: Tirant lo Blanch.

${ }^{8}$ Lev, B. (2003). Intangibles. Mediación, gestión e información. Bilbao: Deusto.

${ }^{9}$ Álvarez Villanueva, C. (2012). Activos Intangibles: catalogación de metodos de valoración. Madrid: Fragua.
} 
Revista Eletrônica de Direito Processual - REDP.

Rio de Janeiro. Ano 15. Volume 22. Número 2. Maio a Agosto de 2021

Periódico Quadrimestral da Pós-Graduação Stricto Sensu em Direito Processual da UERJ

Patrono: José Carlos Barbosa Moreira (in mem.). ISSN 1982-7636. pp. 348-363

www.redp.uerj.br

Já as características é um processo mais complexo e subjetivo, pois visa explicar a natureza, os elementos, qualidades e traços, em razão de seus efeitos positivos e negativos.

Agora, o capital intelectual está dividido em capital humano, capital estrutural e capital relacional. Por capital humano nos referimos à combinação de conhecimentos e habilidades, experiências, habilidades, inventividade e capacidades individuais para realizar certas $\operatorname{tarefas}^{10}$; o capital estrutural é definido como a forma de trabalhar de uma instituição, é assim que fazemos algo, é a capacidade de nos organizarmos, é a forma como juntos alcançamos um objetivo definido, e isso marca um fazer ${ }^{11}$ ou poderíamos chamá-los de usos e costumes, e isso gerou um sistema sob um esquema de melhoria contínua, esse esquema não é aplicável apenas a uma instituição, mas também a uma sociedade, que por sua vez é composta pelo sistema e pelos subsistemas que a constituem. sua organização, e isso também requer capital humano e capital estrutural, para organizá-la e fazê-la funcionar.

Ora, capital relacional, este talvez seja o mais interessante dos três em termos de impacto, pois são todas aquelas relações e efeitos ligados ao processo, à ideia, ao produto, no nosso caso, a política, Capital relacional significa "clientes ", eles são os destinatários dos benefícios gerados por aquela ideia, ela é em si a satisfação de todos os usuários daquele serviço ou produto ${ }^{12}$.

Para seu melhor entendimento, exemplificaremos a operacionalização do capital intelectual em seus três níveis por meio dos MSCs. Devo esclarecer que todos os três devem estar presentes para que cumpram sua missão de dar valor, pois de forma independente eles valem apenas o percentual que sua insinuação justifica. De que adianta um processo se não for executado e não der o resultado para o qual foi criado.

O capital humano centra-se nas competências profissionais e específicas das pessoas, quer dizer que quem o representa são os operadores do MSC, neste caso os negociadores, mediadores / conciliadores, árbitros e facilitadores, são aqueles que possibilitam a gestão e a transformação.

\footnotetext{
${ }^{10}$ Edvission, L., \& Malone, M. (2000). El capital intelectual. Como identificar y calcular el valor de los recursos intangibles de una empresa. Barcelona: Gestion.

${ }^{11}$ Brooking, A. (1997). El capital intelectual. El principal activo de las empresas del tercer milenio. Barcelona: Paidos Empresa.

${ }^{12}$ Edvission, L., \& Malone, M. (2000). El capital intelectual. Como identificar y calcular el valor de los recursos intangibles de una empresa. Barcelona: Gestion.
} 
Revista Eletrônica de Direito Processual - REDP.

Rio de Janeiro. Ano 15. Volume 22. Número 2. Maio a Agosto de 2021

Periódico Quadrimestral da Pós-Graduação Stricto Sensu em Direito Processual da UERJ

Patrono: José Carlos Barbosa Moreira (in mem.). ISSN 1982-7636. pp. 348-363

www.redp.uerj.br

do conflito por causa de suas habilidades e competências, por causa de seu conhecimento sobre o conflito.

O capital estrutural proporciona estabilidade à implementação dos procedimentos de gestão e transformação de conflitos, são então os regulamentos das instituições administrativas da MSC, leis, códigos, normas e convenções nacionais e internacionais, ou seja, o capital estrutural é representado pelos procedimentos concebidos e executados pelo administradores de centros ou institutos de MSC.

Por fim, o capital relacional é o que estabelece o vínculo destes MSCs com a sociedade, gerando as condições de aculturação, é representado pelo que definimos como clientes, são eles os destinatários, são todas aquelas pessoas singulares ou colectivas que se submetem a um MSC, para resolver seus conflitos e aproveitar o resultado.

\section{3.- O valor do bem-estar}

Agora, como identificamos os valores intangíveis de bem-estar? Vamos agora fazer sua analogia em termos de bem-estar. O capital humano é representado por todos aqueles que viabilizam as políticas públicas de bem-estar, ou seja, os profissionais da gestão dos recursos do Estado, dos serviços que deve prestar à comunidade em áreas específicas, saúde, educação, turismo, economia., Comércio, etc., no que diz respeito ao MSC, significa que o Estado deve ter recursos humanos suficientes para a gestão e transformação do conflito.

No que se refere ao capital estrutural, este é representado por protocolos, planos de desenvolvimento, normas municipais, estaduais e nacionais de boa governança, que limitam seus poderes e obrigações que determinam o funcionamento de todos esses serviços geradores de bem-estar, pensemos nos modelos acadêmicos dos diversos níveis educacionais.

Este capital é o que estabiliza estes serviços, que se traduzem na obrigação do Estado de os prestar e no direito dos cidadãos de os receber. O mesmo processo ocorre quando falamos em saúde, economia ou segurança. Quanto aos MSCs, eles já têm o capital estrutural, já estão protegidos pelo Estado. 
Revista Eletrônica de Direito Processual - REDP.

Rio de Janeiro. Ano 15. Volume 22. Número 2. Maio a Agosto de 2021

Periódico Quadrimestral da Pós-Graduação Stricto Sensu em Direito Processual da UERJ

Patrono: José Carlos Barbosa Moreira (in mem.). ISSN 1982-7636. pp. 348-363

www.redp.uerj.br

O capital relacional é representado pelos cidadãos, eles são os destinatários desses processos, daqueles serviços que o Estado presta no regime da previdência. Ele é quem os torna valiosos por meio de seu uso e prazer, mas principalmente por meio de sua aprovação. Seu reconhecimento se dá por meio de sua divulgação, campanhas multidimensionais, que estimulam as pessoas a visualizá-los e exercê-los, como fazem com os direitos humanos, campanhas de saúde, campanhas contra a dengue, promoção do turismo, sendo sua finalidade $\mathrm{O}$ uso e fruição desses serviços, daqueles direitos adquiridos atuando no marco do Estado moderno, situando-os na genética social, para que sua percepção se transforme em um reflexo natural, faça parte de seu cotidiano, faça parte de sua vida com efeito positivo.

Para o seu exercício, é necessária uma visibilidade igual, uma estratégia igual para localizá-los na genética social, para que o cidadão os compreenda como um direito, como um serviço, ao qual deve ter acesso e exigi-los igualmente, pois requerem segurança, eles também requerem luz, água e estabilidade econômica, para citar alguns. Posicionando-os dessa forma, na genética social, para garantir sua implementação e que as pessoas possam resolver seus conflitos a partir de seus interesses na perspectiva do bem-estar subjetivo percebido.

\section{4.- Características distintivas de bem-estar como intangível}

Seguindo o modelo, identifiquemos os traços distintivos do bem-estar, no momento em que concordamos que o bem-estar é um valor intangível, é um valor intangível da sociedade moderna, é um valor intangível dos sistemas de organização e social produção, também é um valor intangível do MSC, como um dos principais benefícios que o acordo de mediação ou conciliação gerará quando um conflito for resolvido; Então, vamos ver quais são essas características dessa última perspectiva.

Produz felicidade

Gerar harmonia

Emoções positivas

Incentive o livre arbítrio 
Revista Eletrônica de Direito Processual - REDP.

Rio de Janeiro. Ano 15. Volume 22. Número 2. Maio a Agosto de 2021

Periódico Quadrimestral da Pós-Graduação Stricto Sensu em Direito Processual da UERJ

Patrono: José Carlos Barbosa Moreira (in mem.). ISSN 1982-7636. pp. 348-363

www.redp.uerj.br

Personalize as decisões de vida

Depende dos nossos interesses

Satisfação plena

Perdão

Gera sinergias de coexistência positiva

Concertação comunitária

Esses traços intangíveis são os mais importantes ou relevantes do bem-estar, porém, isso não implica que identifiquemos mais alguns derivados das ações de bem-estar, dependendo da mesma forma do contexto em que o posicionamos, como alguns deles irão coincidir com os de algum outro valor intangível do MSC, mas, como já comentamos ${ }^{13}$, todos os valores intangíveis do MSC são simbióticos e estão presentes nas suas dimensões, pois o eixo transversal de todos é a gestão e transformação do conflito, que bem poderíamos dizer que são geradores de bem viver, de viver bem.

Os intangíveis não valem por si só, para um intangível adquirir o posto de valioso, depende da sua percepção, é nela que se baseia toda a lógica de avaliação, já havíamos definido no capítulo anterior o que a percepção é, porém, complementando isso, é importante lembrar que percepção é, compreensão e efeito de algo que nos impacta em nosso esquema de vida, é o que sentimos, o que ouvimos, o que vemos, o que saboreamos ou saboreamos, mas mais do que um sentido sensorial , é o conhecimento do bem, do mal, do que gostamos, do que não gostamos, do que nos faz felizes ou infelizes.

\section{5.- Percebendo bem-estar}

Segundo Salazar e Montero ${ }^{14}$, perceber não é receber estímulos passivamente, é selecionar, formular hipóteses, é decidir e processar o que estamos vendo, o que sentimos, a

\footnotetext{
${ }^{13}$ Gorjón Gómez, F. J. (2017). Mediación, su valor intangible y efectos operativos. Una visión integradora de los Métodos Alternos de Solución de Conflictos. México: Tirant lo Blanch.

${ }^{14}$ Salazar, J., Montero, M., \& Et.al. (2012). Percepción Social. Psicología Social, 77 - 109.
} 
Revista Eletrônica de Direito Processual - REDP.

Rio de Janeiro. Ano 15. Volume 22. Número 2. Maio a Agosto de 2021

Periódico Quadrimestral da Pós-Graduação Stricto Sensu em Direito Processual da UERJ

Patrono: José Carlos Barbosa Moreira (in mem.). ISSN 1982-7636. pp. 348-363

www.redp.uerj.br

percepção, como todo processo requer aprendizado, bem como motivação ou emoções, mas no final e em no final, é uma decisão pessoal.

A percepção também depende do estado de espírito e das características das pessoas. Se isso for verdade, vamos pensar sobre este cenário por um momento, quanto mais sensações positivas, maior o bem-estar, maior o bem-estar, maior a felicidade, menos conflitos, maior o bem-estar, quanto maior o número de soluções baseadas em nossos interesses, maior a felicidade, e todas essas conjecturas são matizadas por nossa capacidade de tomada de decisão. A conclusão que este fluxograma nos oferece é que a solução do conflito influencia diretamente nossa percepção, nosso estado de espírito e nosso modo de vida.

Salazar e Montero ${ }^{15}$ nos ilustra por meio de uma série de hipóteses sobre os tipos de influência que determinam o grau de percepção que podemos ter sobre um fenômeno, necessidades corporais, recompensas e punições, características de personalidade, predisposição, estímulos verbais ou ameaças, a velocidade com que reconhecemos o estímulos; O valor que os objetos percebidos têm para os sujeitos também determina a magnitude com que eles os percebem; bem como a predisposição que podemos ter sobre algo.

E se esse algo é violência, e se nos acostumamos a viver na violência, e se fazemos parte dessa violência, o que acontece então, damos entrada em nossas vidas à violência estrutural, fragilizando nosso bem-estar, então, se a gente combinar as várias hipóteses indicadas, a nossa percepção da vida depende das nossas decisões, viver positivamente implica ser positivo, viver negativamente implica ser negativo.

O conflito tem uma base negativa, então seu prolongamento no tempo nos torna negativos e nossa percepção da vida é obviamente influenciada por essa base negativa, então resolver um conflito imediatamente reverte seu efeito negativo, e isso anteriormente nos colocaria em um ambiente negativo, então, nos colocará nos em um ambiente positivo, influenciando nossa percepção de vida, de negativa a positiva, de infeliz a feliz, focando esse efeito que gera bemestar, na tomada de decisão, na tomada de decisão de decisão imediata e não mediata, em a

\footnotetext{
${ }^{15} \mathrm{Idem}$
} 
Revista Eletrônica de Direito Processual - REDP.

Rio de Janeiro. Ano 15. Volume 22. Número 2. Maio a Agosto de 2021

Periódico Quadrimestral da Pós-Graduação Stricto Sensu em Direito Processual da UERJ

Patrono: José Carlos Barbosa Moreira (in mem.). ISSN 1982-7636. pp. 348-363

www.redp.uerj.br

liberdade de decidir, no exercício do nosso livre arbítrio em razão dos nossos interesses, no regime da imediatez do MSC.

\section{6.- Persuasão no bem-estar}

Outro elemento de valor a considerar é a persuasão, uma vez que o modelo IMSC se traduz em uma estratégia de culturização, sendo mais preciso em uma estratégia de comunicação de valores positivos, portanto, é necessário comunicar ou transmitir à sociedade ou aos futuros usuários os benefícios que receberão, os ganhos que serão obtidos com a implementação e integração do MSC em suas vidas como um esquema de bem-estar, ao invés de um sistema de resolução de conflitos.

Teremos que dizer à sociedade que ela vai vencer, por isso me cabe reproduzir a experiência do desenvolvimento do modelo IMSC e citar neste momento ${ }^{16}$ quando ele explica o princípio ganha-ganha, que é ad-hoc adaptado às nossas afirmações.

Vencendo Vencer é uma estrutura de mente e coração que busca constantemente o benefício mútuo em todas as interações humanas. Vencer / Vencer significa que os acordos ou soluções são mutuamente benéficos e mutuamente satisfatórios. Com uma solução ganha-ganha, todas as partes se sentem bem com a decisão tomada e se comprometem com o plano de ação. Vencer / Vencer vê a vida como um cenário cooperativo e não competitivo ", ainda mais ilustrativo quando um dos fatores de bem-estar, como o"Vencer / Vencer "é a nossa capacidade de decidir sobre ela, e este princípio é uma equação de Puro decisão, significa que nosso bem-estar é e depende de nós, em nossa capacidade de determinar o que nos convém e o que não nos convém de nossa prerrogativa inalienável de todas as decisões de vida.

Agora, para isso, temos outro desafio, precisamos persuadir as pessoas disso, os intangíveis não valem por si próprios se as pessoas não os conhecem, o que fazer então? Precisamos transmitir para a sociedade o poder dos valores intangíveis de bem-estar em correlação com os da MSC, transmitir sua funcionalidade principalmente sua simplicidade e

\footnotetext{
${ }^{16}$ Covey, S. (2014). Los 7 habitos de la gente altamente efectiva. México: Paidos.
} 
Revista Eletrônica de Direito Processual - REDP.

Rio de Janeiro. Ano 15. Volume 22. Número 2. Maio a Agosto de 2021

Periódico Quadrimestral da Pós-Graduação Stricto Sensu em Direito Processual da UERJ

Patrono: José Carlos Barbosa Moreira (in mem.). ISSN 1982-7636. pp. 348-363

www.redp.uerj.br

alto desempenho, e como gera benefícios imediatos, para alcançar um efeito de credibilidade nas pessoas pela persuasão, como direito inalienável que os assiste.

Segundo Madero ${ }^{17}$, persuadir não é simplesmente um ato de convencer uma ideia ou uma posição, é uma arte e uma forma de obter o que alguém ou uma comunidade deseja, de forma efetiva, ética e legal, não é um ato de manipulação. Pretendemos satisfazer uma necessidade social, isto é gerar um maior bem-estar para o maior número de pessoas através do MSC, tem a ver com o respeito mútuo e os interesses das partes, elementos igualmente substanciais do MSC.

Para se conseguir uma persuasão efetiva, deve-se transmitir a própria intenção que satisfaça nossas necessidades e interesses, para que tenhamos que entender os desejos das pessoas, entender os critérios que as obrigam a atuar em determinada direção, é preciso apresentar-lhes informações que sejam congruentes. com o que as pessoas querem ou manifestam, portanto, um terreno comum deve ser criado em que possamos unir formas de pensamento e convicções ${ }^{18}$ e este local representa bem-estar, é o ponto de interseção.

Seguindo essa lógica de persuasão, a solução do conflito e a geração de bem-estar através do MSC, mas com maior pontualidade, seu valor intangível de felicidade, assim como o fenômeno de viver bem, de viver bem, será o comum terreno onde seremos capazes de influenciar e persuadir a sociedade a usar os MSCs como uma tela de bem-estar e, consequentemente, criar uma cultura de sua implementação.

A persuasão tem um duplo efeito, para quem é praticada e para quem se destina a convencer. Madero ${ }^{19}$ destaca:

A persuasão é recíproca, pois quando influenciamos uma pessoa, em qualquer sentido, ela também gera o mesmo efeito sobre nós. Quando você ganha uma pessoa para estar em posição de influenciá-la, na verdade ela está ganhando uma à outra e se desenvolve um intercâmbio cultural que reflete o melhor do pensamento de ambas as partes.

\footnotetext{
${ }^{17}$ Madero, M. d. (2010). Persuasión. El poder excepcional. Convence, inspira, seduce. México: Vergara.

${ }^{18}$ Lakhani, D. (2005). Persuasión. El arte de influir y obtener lo que desea. Barcelona: PROFIT.

${ }^{19}$ Madero, M. d. (2010). Ibid.
} 
Revista Eletrônica de Direito Processual - REDP.

Rio de Janeiro. Ano 15. Volume 22. Número 2. Maio a Agosto de 2021

Periódico Quadrimestral da Pós-Graduação Stricto Sensu em Direito Processual da UERJ

Patrono: José Carlos Barbosa Moreira (in mem.). ISSN 1982-7636. pp. 348-363

www.redp.uerj.br

Esse é o verdadeiro objetivo que pretendemos com a promoção e difusão dos intangíveis de MSC em correlação com os de bem-estar, isto em consonância implicará gerar uma sinergia coletiva, para a felicidade das pessoas.

Gerar mudança não é fácil, mas sabemos que toda mudança representa resistência a ela, portanto, temos que estar atentos e ter os elementos de convicção necessários para quebrar essa sinergia e resistência à mudança por meio da persuasão ${ }^{20}$. Portanto, na perspectiva de quem se dedica a resolver conflitos por meio desses novos métodos, isso nos obriga não apenas a definilos ou descrevê-los, somos obrigados a demonstrar sua funcionalidade e viabilidade, para gerar bem-estar, é então através dela a disseminação dos resultados dos valores intangíveis gerados pelo acordo de mediação ou conciliação, são aqueles indicados para demonstrar essa funcionalidade, diante do desafio de que quando falamos de bem-estar e chegamos onde queremos, a subjetividade é o que dita o ritmo, sem No entanto, esta subjetividade é a nossa melhor aliada, pois na sua particularidade é onde se gera a felicidade e é essa particularidade que também marca o acordo MSC.

\section{7.- Tenha pensamentos positivos}

O pensamento positivo transcende para além de uma aptidão que gera atitudes nas pessoas, implica um estilo de vida, implica emoções, implica ações comunitárias que requerem perseverança para transcender e que geram um efeito de mudança ainda mais, quando ${ }^{21}$

A dimensão comunitária do Bem-estar depende do imediato contexto social, O clima emocional do contexto social (trabalho, empresa, comunidade, vizinhança, etc.) está incluído, valores humanos e morais, estabilidade familiar, solidariedade, atitudes de ajuda mútua, civilidade, cortesia, comunicação, cooperação, ausência de violência, integração social, etc. Quanto mais provável houver um contexto comunitário favorável, maior será a probabilidade de uma contribuição social dos membros da comunidade, que

\footnotetext{
${ }^{20}$ Valenzuela Cori, R. (2017). Decidir, jusgar, persuadir. Un ensayo sobre la formación del abogado. México: Tirant Lo Blanch.

${ }^{21}$ Bisquerra, R. (2017). Política y emoción. Aplicaciones de las emociones a la política. Madrid: Piramide.
} 
Revista Eletrônica de Direito Processual - REDP.

Rio de Janeiro. Ano 15. Volume 22. Número 2. Maio a Agosto de 2021

Periódico Quadrimestral da Pós-Graduação Stricto Sensu em Direito Processual da UERJ

Patrono: José Carlos Barbosa Moreira (in mem.). ISSN 1982-7636. pp. 348-363

www.redp.uerj.br

é um elemento-chave para o bem-estar social da comunidade. A dimensão da comunidade é um espaço intermediário entre a dimensão política e a dimensão interpessoal.

A geração de bem-estar requer um contexto comunitário favorável além do material e extra-econômico, sem pensamento positivo isso não é possível, é necessário um esforço extra, seu direcionador é o próprio pensamento positivo.

“A construção do bem-estar pessoal é uma decisão que as pessoas tomam ... criar um clima emocional afeta diretamente a percepção de bem-estar dos cidadãos ... o bem-estar se constrói e o que é mais importante, aprende-se a ser feliz ", parafraseando Bisquerra ${ }^{22}$, o contágio das

emoções é necessário, é necessário criar climas emocionais positivos que favoreçam a convivência e o bem-estar. Por isso, um mediador ou agente de paz deve pensar e conviver positivamente com outras competências, entre as quais se destacam:

- Promotor da paz;

- Resolver conflitos por meio de mediação e outros MSCs (negociação, conciliação, composição amigável, arbitragem);

- É promotora da cultura de acordo, diálogo, perdão, felicidade;

- E é aquele que educa para a paz estrutural e vive pela paz.

Isso permitirá que os cidadãos sejam agentes ativos na gestão e transformação dos seus conflitos, ou, se for o caso, usufruam da oportunidade de recorrer à mediação para também gerir e transformar os seus conflitos, devido ao seu bem-estar subjetivo percebido.

\section{REFERÊNCIAS}

ÁLVAREZ VILLANUEVA, C. (2012). Activos Intangibles: catalogación de metodos de valoración. Madrid: Fragua.

BISQUERRA, R. (2017). Política y emoción. Aplicaciones de las emociones a la política. Madrid: Piramide.

${ }^{22}$ Idem 
Revista Eletrônica de Direito Processual - REDP.

Rio de Janeiro. Ano 15. Volume 22. Número 2. Maio a Agosto de 2021

Periódico Quadrimestral da Pós-Graduação Stricto Sensu em Direito Processual da UERJ

Patrono: José Carlos Barbosa Moreira (in mem.). ISSN 1982-7636. pp. 348-363

www.redp.uerj.br

BROOKING, A. (1997). El capital intelectual. El principal activo de las empresas del tercer milenio. Barcelona: Paidos Empresa.

COVEY, S. (2014). Los 7 habitos de la gente altamente efectiva. México: Paidos.

EDVISSION, L., \& Malone, M. (2000). El capital intelectual. Como identificar y calcular el valor de los recursos intangibles de una empresa. Barcelona: Gestion.

FEBRE, L. (2006). El pensamiento positivo y su efecto en la comunicación. Buenos Aires: Lumen.

GERSHI, C. A. (2018). Los costos, costes y costas en la resolución de conflictos. México: Tirant Lo Blanch.

GORJÓN GÓMEZ, F. J. (2017). Mediación, su valor intangible y efectos operativos. Una visión integradora de los Métodos Alternos de Solución de Conflictos. México: Tirant lo Blanch.

GORJÓN-GÓMEZ, F. (2019). Mediador y Facilitador. El mediador profesional del acuerdo, el facilitador profesional del perdón. JUIRIS POIESIS, 229 - 252.

LAKHANI, D. (2005). Persuasión. El arte de influir y obtener lo que desea. Barcelona: PROFIT.

LEV, B. (2003). Intangibles. Mediación, gestión e información. Bilbao: Deusto.

MADERO, M. d. (2010). Persuasión. El poder excepcional. Convence, inspira, seduce. México: Vergara.

MUÑOZ, R. (12 de Noviembre de 2019). Tesis Doctoral. La felciadad como valor intengible de la mediación. Monterrey, Nuevo León, México: UANL.

RAMOS MORALES, M. L. (17 de Mayo de 2017). Tesis Doctoral. Los elementos del perdon en la mediación familiar. Monterrey, Nuevo León, México: UANL.

SACIPA RODRIGUEZ, S. (2005). Las y los ciudadanos de Bogota significan la paz. Universitas Psichologica, 1 - 25.

SALAZAR, J., Montero, M., \& Et.al. (2012). Percepción Social. Psicología Social, 77 - 109.

TOROTOSA BLASCO, J. M. (2003). Violencia estructural una ilustración del concepto. Documentación social, 57 - 72. 
Revista Eletrônica de Direito Processual - REDP.

Rio de Janeiro. Ano 15. Volume 22. Número 2. Maio a Agosto de 2021

Periódico Quadrimestral da Pós-Graduação Stricto Sensu em Direito Processual da UERJ

Patrono: José Carlos Barbosa Moreira (in mem.). ISSN 1982-7636. pp. 348-363

www.redp.uerj.br

VALENZUELA CORI, R. (2017). Decidir, jusgar, persuadir. Un ensayo sobre la formación del abogado. México: Tirant Lo Blanch. 